\title{
Current Prophylactic Hypothermia for Intracranial Hypertension after Traumatic Brain Injury
}

\author{
Joohyun Kim, Sang-Hoon Lee, Junseok W Hur, Kyung-Jae Park, Jang-Bo Lee, Shin-Hyuk Kang, \\ Tai-Hyoung Cho, Jung-Yul Park, Yong-Gu Jung, Dong-Hyuk Park
}

Department of Neurosurgery, Anam Hospital, Korea University College of Medicine, Seoul, Korea

Received: October 16, 2020

Accepted: October 19, 2020

Corresponding Author:

Dong-Hyuk Park, MD, PhD

Department of Neurosurgery,

Anam Hospital, Korea University

College of Medicine, 73, Inchon-

ro, Seongbuk-gu, Seoul 02841,

Korea

Tel: +82-2-920-6833

Fax: +82-2-929-0629

E-mail: doctorns@korea.com

\begin{abstract}
Hypothermia performed in patients with traumatic brain injury (TBI) reduces cerebral metabolism and cerebral blood flow, subsequently decreasing intracranial pressure (ICP). There have been many disagreements about the effectiveness of prophylactic hypothermia in its clinical application. Until now, hypothermia has been used without standardized treatment guidelines and performed by each medical provider's personal judgment. Recently, a large-scale randomized controlled trial regarding hypothermia was conducted, and it concluded that the early use of therapeutic hypothermia in the staged management of ICP elevation is not beneficial. Therefore, it is our latest knowledge that it is difficult to derive a standardized treatment protocol for prophylactic hypothermia in TBI patients, and also, it is not advantageous to the patient.
\end{abstract}

Keywords: Hypothermia; Traumatic brain injury; Intracranial pressure; Intracranial hypertension

\section{INTRODUCTION}

After a report on the effect of hypothermia on minimizing brain damage following cardiac arrest, many hypothermia studies have been conducted on patients with traumatic brain injury $(\mathrm{TBI})^{1-3)}$. Among them, there were studies that hypothermia in TBI patients lowers intracranial pressure (ICP) caused by cerebral edema and improves the patient's outcome ${ }^{4)}$. On the other hand, in a recent multicenter randomized controlled trial (RCT) study in adults, the authors concluded that the effect of hypothermia treatment could not be confirmed ${ }^{5)}$. There have been disagreements regarding the effectiveness of hypothermia for patients with TBI. A large number of medical providers are in effort to set a standard treatment guideline for hypothermia after TBI patients to use hypothermia as a complementary treatment option of controlling ICP. Since then, large-scale studies have been conducted on the application of hy- pothermia to patients with TBI in various centers under different conditions. Therefore, we would like to examine the possibility of deriving a standard treatment guideline by analyzing the clinical applications and treatment outcome of hypothermia for patients with TBI, recently published through several large-scale studies.

\section{PATHOPHYSIOLOGY}

When the body temperature decreases, the brain's metabolism decreases by $6-10 \%$ per degree, and the energy demand decreas$\mathrm{es}^{6}$. As the cell membrane is stabilized, the indiscriminate influx of sodium and calcium ions and consequent cerebral edema decreas$\mathrm{es}^{7}$. In addition, hypothermia suppresses apoptosis, reduces the influx of polymorphonuclear leukocytes into the brain tissue and secretion of cytokines, thereby reducing the inflammatory response. As a result, it shows a neuroprotective effect and a decrease

Copyright (C) 2020 The Korean Neurointensive Care Society

This is an Open Access article distributed under the terms of the Creative Commons Attribution Non-Commercial License (http://creativecommons.org/licenses/by-nc/4.0/) which permits unrestricted non-commercial use, distribution, and reproduction in any medium, provided the original work is properly cited. 
in ICP caused by ischemia or $\mathrm{TBI}^{8,9)}$.

\section{CLINICALAPPLICATIONS OF HYPOTHERMIA}

Hypothermia was induced for TBI patients who were unresponsive to stage 1 treatments (defined as mechanical ventilation, sedation, head of bed to $30^{\circ}$, analgesia, cerebral perfusion pressure optimization, +/- ventriculostomy, or +/- surgical removal of space-occupying lesions) and who were ICP of $>20$ $\mathrm{mmHg}$ for at least 5 minutes ${ }^{10,11)}$. A bolus of intravenous, refrigerated $0.9 \%$ sodium chloride ( 20 to $30 \mathrm{ml}$ per kilogram of body weight) was administered and after that maintained with each site's usual cooling technique. Patients randomized into the hypothermia group received therapeutic temperature modulation (TTM) with an initial target of $35^{\circ} \mathrm{C}^{12}$ ) but the temperature was lowered incrementally down to as low as $32{ }^{\circ} \mathrm{C}$ until ICP was below $20 \mathrm{mmHg}$. Hypertonic solutions were then administered only if hypothermia was ineffective. Patients in the control group received hypertonic solutions once stage- 1 therapies had failed to bring the ICP to $\leq 20 \mathrm{mmHg}$. Once hypothermia started, it was maintained for at least $48 \mathrm{~h}$ and then re-warmed at a rate of $0.25^{\circ} \mathrm{C}$ per hour if ICPs were under control. The primary outcome was scored using the Extended Glasgow Outcome Scale (GOS-E) at 6 months (Fig. 1) ${ }^{11)}$.

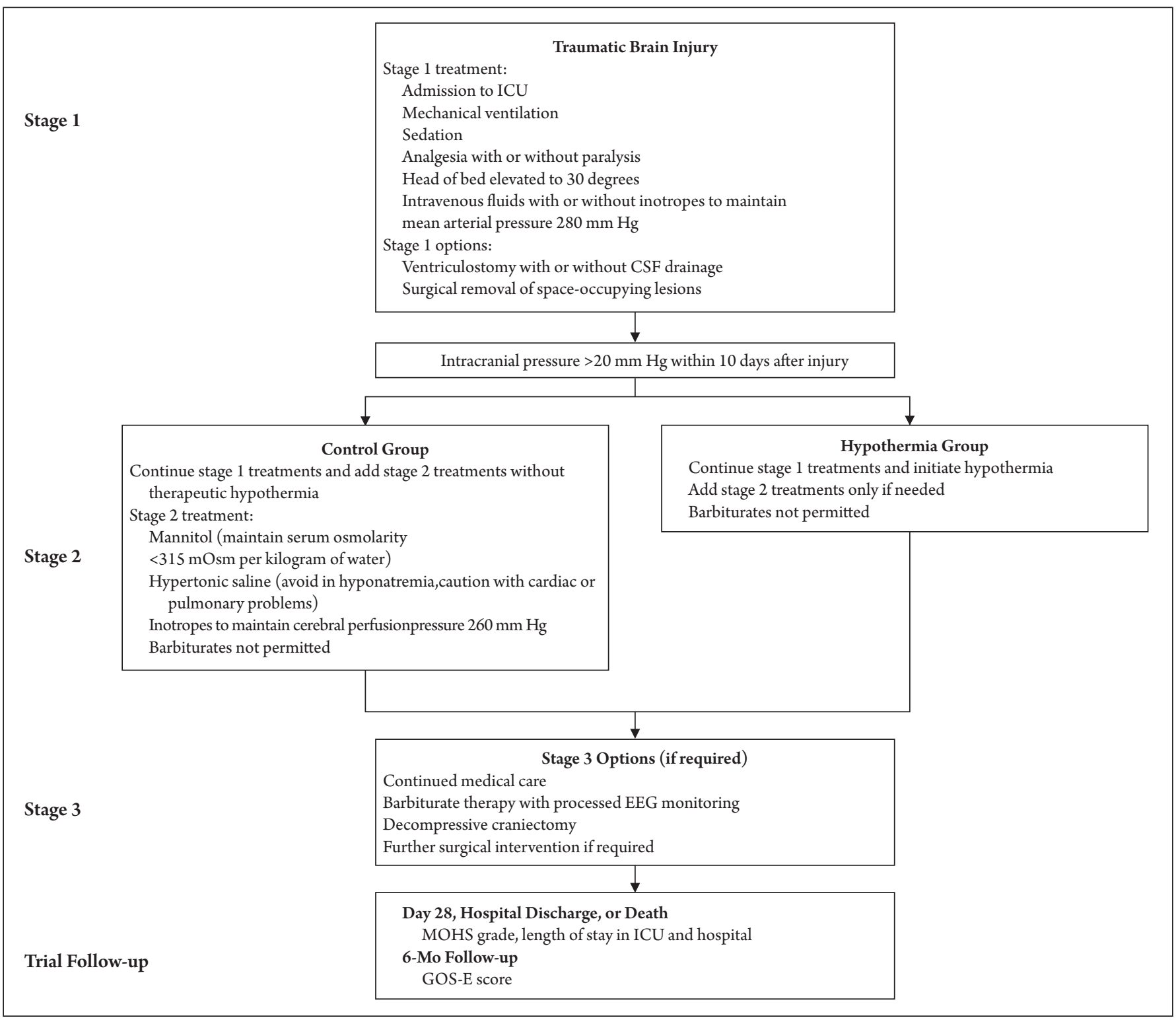

Fig. 1. Stages of therapeutic management and trial follow-up (adopted from Andrews PJ et al.) ${ }^{11}$. CSF, denotes cerebrospinal fluid; EEG, electroencephalographic; GOS-E, Extended glasgow outcome scale; ICU, intensive care unit; MOHS, modified oxford handicap scale. 


\section{TREATMENT EFFECT OF HYPOTHERMIA}

According to the previously published meta-analysis regarding the role of hypothermia in patients with TBI, hypothermia showed significant improvement on survival rate and functional recovery rate ${ }^{13,14)}$. Contrary to the previous knowledge, a recently conducted multicenter RCT study concluded that hypothermia did not lead to any positive outcomes than conventional treatment ${ }^{11,15,16)}$. While prophylactic hypothermia after TBI has been extensively studied in the "National Acute Brain Injury Study: Hypothermia" $(\mathrm{NABISH})^{15)}$ trials and "Prophylactic Hypothermia Trial to Lessen Traumatic Brain Injury” (POLAR) RCT with little success, the specific use of "late-rescue" hypothermia to treat intracranial hypertension after TBI has acquired less attention ${ }^{16)}$. EuroTherm3235, another open-label RCT study, compared use versus non-use of hypothermia prior to administering hypertonic solutions as a part of a staged treatment of intracranial hypertension after $\mathrm{TBI}^{11}{ }^{11}$. In contrast to expectations, hypothermia did not show a superior effect compared to conventional treatment in large-scale studies. One of the possible explanations for no change would be the timing of rewarming coinciding with the point at which cerebral edema worsen ${ }^{17)}$. Other feasible reasons include TBI's mechanism being different from that of brain injury caused by cardiac arrest and medical provider's ineptness in controlling the patient's fluid volume and blood pressure ${ }^{17)}$.

The trial was initially designed to enroll 600 patients. However, it terminated early after recording and randomizing 387 subjects due to undesirable outcomes in the hypothermia group. The adjusted common odds ratio for the GOS-E score was 1.53 (95\% confidence interval, 1.02 to $2.30 ; \mathrm{P}=0.04$ ), indicating that the hypothermia group had a more unsatisfactory outcome than in the control group. A favorable outcome (GOS-E score of 5 to 8, indicating moderate disability or good recovery) was yielded in $26 \%$ of the patients in the hypothermia group compared to $37 \%$ in the control group $(\mathrm{p}=0.03)^{11)}$. This trial addressed convincing evidence that application of hypothermia to $32-35^{\circ} \mathrm{C}$ likely has more risks than benefits for treatment of intracranial hypertension in $\mathrm{TBI}^{10)}$.

However, many centers still perform hypothermia when the following conditions arise during the treatment of traumatic brain injury patients, and these conditions have not been studied in Eurotherm 3235 trials $^{10)}$.

a) Use only after hypertonic solutions have failed,

b) For more severe ICP elevations ( $>25-30 \mathrm{mmHg}$ ), or

c) Only after barbiturate coma has failed.
The efficacy of hypothermia in these clinical situations remains unclear, especially with patients who have severe, refractory elevated ICP. Many centers still continue to utilize TTM management to $33^{\circ} \mathrm{C}$ for patients with ICP $>25 \mathrm{mmHg}$ who have failed hypertonic solutions in order to reduce the use of barbiturate-induced coma. However, there is no evidence refuting nor supporting this treatment.

\section{CONCLUSION}

The early use of therapeutic hypothermia in the staged management of ICP elevation is not beneficial ${ }^{10)}$. There is also growing evidence that prophylactic hypothermia does not improve patients outcomes and does not have a significant effect on intracranial hypertension. As stated in the earlier NABISH trials, it is our latest knowledge that it is difficult to derive a standard treatment protocol for prophylactic hypothermia in TBI patients, and also it is not beneficial to the patient.

\section{NOTES}

\section{Conflict of interest}

No potential conflict of interest relevant to this article was reported.

\section{Acknowledgements}

The authors thank Dr. Jennifer Bai for her help in manuscript translation.

\section{REFERENCES}

1. Holzer M, Mullner M, Sterz F, Robak O, Kliegel A, Losert H, et al. Efficacy and safety of endovascular cooling after cardiac arrest: cohort study and Bayesian approach. Stroke 2006;37: 1792-1797.

2. Bernard SA, Gray TW, Buist MD, Jones BM, Silvester W, Gutteridge G, et al. Treatment of comatose survivors of out-of-hospital cardiac arrest with induced hypothermia. N Engl J Med 2002;346:557-563.

3. Hypothermia after Cardiac Arrest Study Group. Mild therapeutic hypothermia to improve the neurologic outcome after cardiac arrest. N Engl J Med 2002;346:549-556.

4. Polderman KH. Induced hypothermia and fever control for prevention and treatment of neurological injuries. Lancet 2008;371:1955-1969.

5. Clifton GL, Miller ER, Choi SC, Levin HS, McCauley S, Smith $\mathrm{KR} \mathrm{Jr}$, et al. Lack of effect of induction of hypothermia after 
acute brain injury. N Engl J Med 2001;344:556-563.

6. Steen PA, Newberg L, Milde JH, Michenfelder JD. Hypothermia and barbiturates: individual and combined effects on canine cerebral oxygen consumption. Anesthesiology 1983;58: $527-532$.

7. Vaquero J, Rose C, Butterworth RF. Keeping cool in acute liver failure: rationale for the use of mild hypothermia. J Hepatol 2005;43:1067-1077.

8. Polderman KH. Mechanisms of action, physiological effects, and complications of hypothermia. Crit Care Med 2009;37(7 Suppl):S186-202.

9. Polderman KH, Herold I. Therapeutic hypothermia and controlled normothermia in the intensive care unit: practical considerations, side effects, and cooling methods. Crit Care Med 2009;37:1101-1120.

10. Changa AR, Czeisler BM, Lord AS. Management of Elevated Intracranial Pressure: a Review. Curr Neurol Neurosci Rep 2019;19:99.

11. Andrews PJ, Sinclair HL, Rodriguez A, Harris BA, Battison CG, Rodriguez A, et al. Hypothermia for Intracranial Hypertension after Traumatic Brain Injury. N Engl J Med 2015;373:24032412.
12. Jiang J, Yu M, Zhu C. Effect of long-term mild hypothermia therapy in patients with severe traumatic brain injury: 1-year follow-up review of 87 cases. J Neurosurg 2000;93:546-549.

13. Peterson K, Carson S, Carney N. Hypothermia treatment for traumatic brain injury: a systematic review and meta-analysis. J Neurotrauma 2008;25:62-71.

14. Georgiou AP, Manara AR. Role of therapeutic hypothermia in improving outcome after traumatic brain injury: a systematic review. Br J Anaesth 2013;110:357-367.

15. Clifton GL, Valadka A, Zygun D, Coffey CS, Drever P, Fourwinds $\mathrm{S}$, et al. Very early hypothermia induction in patients with severe brain injury (the National Acute Brain Injury Study: Hypothermia II): a randomised trial. Lancet Neurol 2011;10:131139.

16. Cooper DJ, Nichol AD, Bailey M, Bernard S, Cameron PA, Pili-Floury S, et al. Effect of early sustained prophylactic hypothermia on neurologic outcomes among patients with severe traumatic brain injury the POLAR randomized clinical trial. JAMA 2018;320:2211-2220.

17. Choi HA, Badjatia N, Mayer SA. Hypothermia for acute brain injury--mechanisms and practical aspects. Nat Rev Neurol 2012;8:214-222. 